\title{
Current Perspectives on the Diagnosis and Management of Primary Urethral Cancer: A Systematic Review
}

\section{Ryan Farrell Jonathan $\mathrm{T} X \mathrm{Xu}$ Alex J Vanni}

Center for Reconstructive Urologic Surgery, Lahey Hospital and Medical Center, Burlington, MA, USA
Correspondence: Alex J Vanni Center for Reconstructive Urology Surgery, Lahey Hospital and Medical Center, 4I Mall Road, Burlington, MA, 0I805, USA

Tel + I 78I 7448420

Email alex.j.vanni@lahey.org

\begin{abstract}
Primary urethral cancer (PUC) is a rare but highly aggressive malignancy that causes malignant urethral obstruction. We conducted a literature review using PubMed to identify original research studies that assessed the diagnosis and management of primary urethral cancer. PUC affects men more than women, is more common in African Americans than Caucasians, and is associated with history of chronic inflammation and irritation of the urinary tract. Patients suspected of PUC should undergo a complete work-up including cystoscopy, magnetic resonance imaging, and biopsy. In men and women, surgical monotherapy ranging from organ-sparing to more radical reconstructive procedures has adequate survival rates for early stage PUC and has been shown to be similarly as effective as radiation monotherapy, while multimodal therapy has become the standard of treatment for advanced stage PUC. Salvage surgery or radiation therapy has been linked with increased survival rates. Nodal involvement at the time of diagnosis is a negative prognosticator and should be treated with multimodal therapy. Further prospective studies with greater sample sizes and standardized clinical trials would allow for greater consistency in evaluating the different treatment modalities for PUC.
\end{abstract}

Keywords: chemotherapy, multimodal treatment, operative procedures, radiotherapy, surgical procedures, urethral cancer

\section{Introduction}

Primary urethral cancer (PUC) is the principle cause of malignant urethral obstruction. Although rare, PUC is aggressive and becomes more difficult to treat if not diagnosed early irrespective of race, gender, and location. Risk factors include chronic inflammation and irritation of the urethra, human papilloma virus (HPV), and for females, urethral diverticula. Urethral tumors are categorized based on location and histology; work-up typically involves an extensive physical exam with imaging. While surgery and radiation therapy remain the mainstay treatment options for localized or early stage disease, advanced-stage disease typically requires multimodal treatment.

Given the rarity of the disease, current studies in the literature are mostly retrospective analyses with small sample sizes and heterogenous cohorts. As a result, there continues to be controversy regarding optimal treatment modalities. This article aims to comprehensively describe the epidemiology, etiology, and clinical work-up for 
PUC. Further, we review the literature on treatment modalities for PUC in the male and female urethra.

\section{Methods}

A literature review search was performed by a single reviewer according to the PRISMA standards. PubMed was used to identify manuscripts that evaluated management and associated survival data for (1) PUC in the anterior male urethra, (2) PUC in the prostatic urethra, (3) PUC in the anterior female urethra, and (4) PUC in the posterior female urethra.

The preliminary literature search identified 1151 potential articles. Exclusion criteria for articles included case reports, nonsystematic reviews, letters, opinion, and manuscripts that were not pertinent to the topic of this review. All included studies were in English. Each title and/or abstract from the preliminary search was reviewed to determine if it was pertinent to the topic of review. The full text of 83 articles were screened for eligibility and 39 articles were included in this systematic review. (Figure 1)

\section{Epidemiology}

PUC accounts for less than $1 \%$ of all malignancies worldwide. ${ }^{1-3}$ Based on a study from the National Cancer Institute Surveillance, Epidemiology, and End Results (SEER) database, the estimated prevalence of PUC in North America is roughly 4.3 per million and 1.5 per million for men and women, respectively. ${ }^{3}$ While it has been previously reported that rates of PUC were more common in females than males, ${ }^{4}$ more recent studies have identified a 2:1 male to female predominance. ${ }^{3}$ Swartz et al demonstrated that men and women greater than age 75 had a higher incidence of PUC. In addition, there was a 2:1 predominance of PUC in African-American men compared to Caucasian men and a nearly 3:1 incidence rate of PUC in AfricanAmerican women compared to Caucasian women.

\section{Etiology}

Risk factors for PUC are multifactorial and differ slightly between men and women. In men, chronic inflammation from a history of sexually transmitted infections (specifically HPV-16), urethral stricture, irritation from intermittent catheterization as well as history of radiation therapy have all been shown to increase risk of PUC. ${ }^{5-7}$ In women, sexually transmitted infections and chronic inflammation and irritation from urinary tract infections are risk factors for developing PUC. In addition, urethral diverticula are associated with an increased risk of developing female PUC, especially adenocarcinoma. ${ }^{8-10}$

\section{Clinical Presentation}

The male urethra is subdivided into anterior (fossa navicularis, penile urethra, and bulbar urethra) and posterior (membranous urethra, prostatic urethra) segments. The

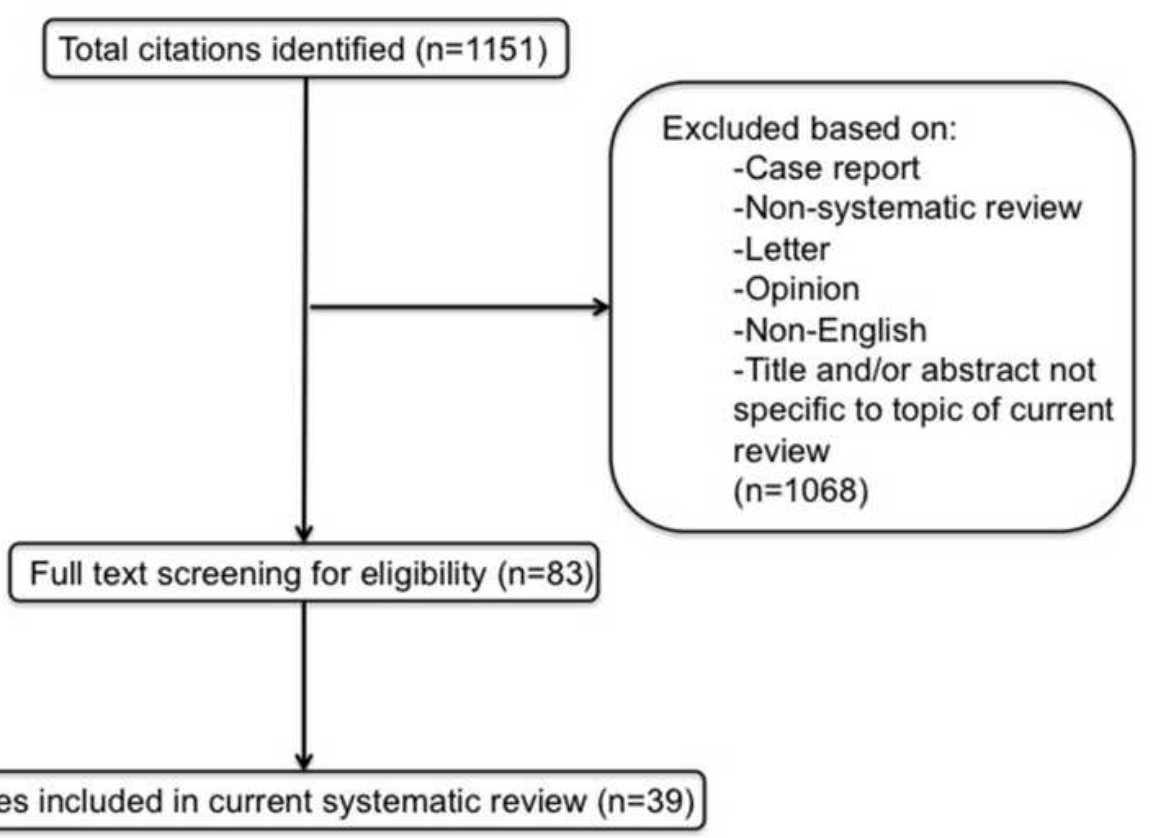

Figure I Flow diagram outlining article identification and selection based on PRISMA criteria. 
lymphatics from the anterior urethra drain sequentially into the superficial and deep inguinal nodes and then into pelvic lymph nodes (external iliac), while lymphatics from the posterior urethra drain into the pelvic lymph nodes. ${ }^{11}$

Tumors of the male urethra are typically categorized by location and histology. The bulbomembranous urethra is most frequently involved, accounting for $60 \%$ of tumors, followed by the penile and prostatic urethra. A SEER study by Rabbani showed that urothelial carcinoma (77.6\%) made up the majority of primary urethral cancers, followed by squamous cell (11.9\%), adenocarcinoma (5\%), and other histologies (5.5\%). ${ }^{12}$ Tumor histology also varies depending on location within the urethracarcinomas in the prostatic urethra are primarily urothelial/transitional cell in origin, while carcinomas in the penile and bulbomembranous urethra are more likely to be squamous cell. ${ }^{13}$

Men with PUC may present with obstructive or irritative voiding symptoms such as dysuria, decreased urinary stream, urinary retention, and perineal pain. ${ }^{14}$ Other symptoms on presentation may include hematuria, urethral discharge, general pelvic pain, penile or urethral mass, stricture, or urethrocutaneous fistula. ${ }^{7,15-17}$

The female urethra is much shorter than the male urethra and is typically 3 to $4 \mathrm{~cm}$ in length. It is divided into an anterior segment (distal third) and a posterior segment (proximal two thirds), which is an important distinction when considering surgical treatment. The proximal third of the female urethra is lined by transitional urothelium while the distal two thirds are lined by stratified squamous urothelium. The lymphatics of the posterior female urethra drain into the pelvic lymph nodes (internal iliac, external iliac, and obturator lymph node chains) while the anterior female urethra and labia drain into the superficial and subsequently deep inguinal lymph nodes. ${ }^{18}$

In contrast to urethral cancer in males, PUC in the female typically occurs along the entire length of the urethra. ${ }^{14}$ Furthermore, with regards to histology, urothelial carcinoma is the most common tumor type in female PUC (30-45\%), followed by adenocarcinoma (29\%) and squamous cell carcinoma (19-28\%) according to SEER data and a study from the Netherlands National Cancer Registry. ${ }^{3,19}$ The incidence rate of adenocarcinoma (0.26-1.4 cases/million person years; PY) is higher than urothelial carcinoma (0.12-0.7 cases/million PY) and squamous cell carcinoma (0.12-0.76 cases/million PY) among females age 35-64. However, among women 65-84 years of age, the incidence rate of adenocarcinoma
(1.5-1.6 cases/million PY) drops below urothelial (2.1-3.7 cases/million PY) and squamous cell carcinoma (1.9-2.9 cases/million PY). ${ }^{3}$

PUC adenocarcinoma is observed more often in women than men and is thought to arise from Skene's ducts. ${ }^{20}$ The two predominant histologic subtypes of adenocarcinoma are clear cell and columnar/mucinous. The clear cell subtype arises from the distal aspect of the duct and can be positive for prostate specific antigen (PSA) whereas the columnar/mucinous subtype arises from the proximal aspect of the duct, is similar to colonic or endocervical adenocarcinoma, and is carcinoembryonic antigen positive. $^{21}$

The majority of women diagnosed with PUC are symptomatic at the time of presentation, with greater than $70 \%$ of women reporting recurrent urinary tract infections, irritative voiding symptoms, or dyspareunia, while obstructive voiding and hematuria are less common presenting symptoms. $^{22}$

\section{Clinical Evaluation}

Clinical evaluation of patients with symptoms concerning for PUC begins with a thorough physical examination of external genitalia including a rectal exam for men and pelvic examination with palpation of the urethra in women. Evaluation of the inguinal region for lymphadenopathy in both sexes is essential. ${ }^{7}$ Voided urine cytology is not a robust marker for PUC both in males and females, as a positive cytology has been noted in $59 \%$ of patients with biopsy-proven PUC. ${ }^{23}$ Instead, work-up for suspected PUC often includes bimanual examination under anesthesia and cystoscopy, which may be useful in clinical staging of the disease. Tissue diagnosis of a urethral lesion is mandatory prior to pursuing treatment. Distal lesions can simply be excised for tissue diagnosis; however, proximal tumors can be more challenging to biopsy. Several techniques have been described including cystoscopy with coldcup biopsy forceps or transurethral/percutaneous approach using a 14-gauge Temno biopsy needle. ${ }^{7}$ Urothelial tumors of the prostatic urethra can be biopsied with resectoscope loop, taking care to avoid resection distal to the verumontanum so as not to injure the external sphincter. ${ }^{24}$

With regard to imaging, a computed tomography (CT) scan of the chest, abdomen, and pelvis is highly recommended for evaluating cancer involvement in the soft tissue and lymph nodes, as well as identifying distant metastases. The CT scan should include pre and postcontrast images along with delayed series to allow for 
evaluation of the entire urinary tract. More recently, magnetic resonance imaging (MRI) has been shown in the literature to be a superior imaging modality for staging initial disease due to its high sensitivity for assessing local tumor involvement, as well as to evaluate response to chemoradiation therapy. ${ }^{25,26}$

\section{Staging}

Male and female PUC are both staged according to the tumor, nodes, and metastases (TNM) classification system (Table 1). ${ }^{27}$ Similar to other malignancies, it is based on depth of invasion of the primary tumor and the presence and absence of regional lymph node involvement and distant metastases. A further distinction of PUC that is not directly measured by the TNM staging system is tumor location in the urethra, which is an important factor in determining PUC outcomes. ${ }^{7}$ PUC tumors occurring in the prostatic, membranous, and bulbar urethra are historically referred to as "proximal", while tumors involving the penile urethra and fossa navicularis are referred to as "distal".

\section{Management and Outcomes \\ Male Anterior Urethral Cancer}

Penile Urethra

Tumors of the penile urethra are particularly amenable to surgical resection. The extent of surgical resection varies from distal urethrectomy for tumors of the distal penile urethra or fossa navicularis to complete urethrectomy with perineal urethrostomy for proximal penile urethral lesions. Partial or total penectomy can be utilized if necessary in order to achieve a negative margin of $5 \mathrm{~mm} .^{28-30}$

Smith et al have further highlighted options for penile preserving surgery in a retrospective study of 18 patients with tumors limited to the meatus, fossa navicularis and penile urethra. For tumors at the urethral meatus, a hypospadic meatus was created to allow for application of topical 5-fluorouracil cream $(n=3)$. Fossa navicularis and distal penile urethral tumors were managed with a two-stage Johanson urethroplasty $(n=4)$. Patients with tumors invading the glans underwent glansectomy $(n=3)$, while tumors with more extensive involvement of the glans and distal corpora cavernosa underwent glansectomy with distal corporectomy and hypospadias formation $(n=6)$. Large tumors of the distal penile urethra or those with multifocal disease were managed with distal urethrectomy,
Table I Tumor, Nodes, and Metastases (TNM) Classification of Urethral Carcinoma

\begin{tabular}{|c|c|}
\hline \multicolumn{2}{|c|}{ Male and Female Urethra } \\
\hline \multicolumn{2}{|c|}{ T: Primary tumor } \\
\hline$T x$ & Primary tumor cannot be assessed \\
\hline T0 & No evidence of primary tumor \\
\hline $\mathrm{Ta}$ & Noninvasive papillary carcinoma \\
\hline Tis & Carcinoma in situ \\
\hline TI & Tumor invades subepithelial connective tissue \\
\hline T2 & $\begin{array}{l}\text { Tumor invades any of the following: corpus spongiosum, } \\
\text { periurethral muscle }\end{array}$ \\
\hline T3 & $\begin{array}{l}\text { Tumor invades any of the following: corpus cavernosum, } \\
\text { anterior vagina }\end{array}$ \\
\hline T4 & Tumor invades other adjacent organs \\
\hline \multicolumn{2}{|c|}{ Prostatic urethra } \\
\hline \multicolumn{2}{|c|}{ T: Primary tumor } \\
\hline Tx & Primary tumor cannot be assessed \\
\hline T0 & No evidence of primary tumor \\
\hline $\mathrm{Ta}$ & Noninvasive papillary carcinoma \\
\hline Tis & $\begin{array}{l}\text { Carcinoma in situ involving prostatic urethra or periurethral or } \\
\text { prostatic ducts without stromal invasion }\end{array}$ \\
\hline TI & $\begin{array}{l}\text { Tumor invades urethral subepithelial connective tissue } \\
\text { immediately underlying the urothelium }\end{array}$ \\
\hline $\mathrm{T} 2$ & $\begin{array}{l}\text { Tumor invades prostatic stroma surrounding ducts either by } \\
\text { direct extension from the urothelial surface or by invasion from } \\
\text { prostatic ducts }\end{array}$ \\
\hline T3 & Tumor invades the periprostatic fat \\
\hline T4 & Tumor invades other adjacent organs \\
\hline \multicolumn{2}{|c|}{ N: Regional lymph nodes } \\
\hline Nx & Regional lymph nodes cannot be assessed \\
\hline No & No regional lymph node metastasis \\
\hline NI & $\begin{array}{l}\text { Single regional lymph node metastasis in the inguinal region or } \\
\text { true pelvis (perivesical, obturator, external or internal iliac) or } \\
\text { presacral lymph node }\end{array}$ \\
\hline N2 & $\begin{array}{l}\text { Multiple regional lymph node metastases in the inguinal region } \\
\text { or true pelvis (perivesical, obturator, external or internal iliac) } \\
\text { or presacral lymph node }\end{array}$ \\
\hline \multicolumn{2}{|c|}{ M: Distant metastasis } \\
\hline MO & No distant metastasis \\
\hline MI & Distant metastasis \\
\hline
\end{tabular}

Notes: American Joint Committee on Cancer. The AJCC cancer staging manual, 8th edition. Am Coll Surg. 2018. Used with permission of the American College of Surgeons, Chicago, Illinois. The original source for this information is the AJCC Cancer Staging System (2020). ${ }^{27}$

excision of any involved tunica albuginea and creation of a perineal urethrostomy $(n=2)$. No local recurrences were observed at a median follow-up of 26 months, however, four patients had progression with regional 
lymph node involvement and two patients died of disease. $^{30}$

Radiation may be offered to patients with earlier stage disease who decline surgery and prefer an organ sparing approach, however, there are sparse data on outcomes. Patients should be counseled that radiation is associated with a risk of skin necrosis, fistula, and urethral stricture that may ultimately require surgical intervention. ${ }^{31}$

Combination chemoradiation is an option for patients with advanced disease who desire a potentially organ sparing treatment or are poor surgical candidates. Cohen et al initially developed a chemoradiation regimen that was adapted from the Nigro protocol for squamous cell carcinoma of the anus. ${ }^{32,33}$ This consisted of two cycles of 5-fluorouracil and mitomycin $\mathrm{C}$ with concurrent external beam radiation therapy to the genitalia, perineum, inguinal and external iliac lymph nodes. ${ }^{32}$ Kent et al later provided updated data from the same institution that included 29 patients, of which $88 \%$ had $\geq \mathrm{T} 3$ disease or lymph node metastasis. ${ }^{15}$ Tumors arising from the penile urethra were present in 12 (41\%); however, outcomes were not stratified by tumor location. Diseasefree survival at five years was $43 \%$ and the five-year overall survival was $52 \%$. Patients that did not respond to chemoradiation and those with disease recurrence underwent consolidation salvage surgery. It is important to note that all patients with appreciable disease-free survival developed radiation induced urethral strictures (Table 2).

Distinct from penile cancer, clinically enlarged lymph nodes at the time of initial presentation of PUC are less likely to represent inflammation and more likely to be associated with metastatic disease. ${ }^{34}$ Further, there is no clear role for prophylactic inguinal lymphadenectomy for PUC of the penile urethra in the setting of clinically negative lymph nodes. Palpable inguinal lymph nodes can be controlled with neoadjuvant chemotherapy followed by inguinal lymphadenectomy. ${ }^{30}$ An alternative is upfront chemoradiation for node-positive disease followed by salvage surgery for nonresponders or those with recurrent disease. The latter approach potentially reduces the number of patients requiring surgery and its associated morbidity. ${ }^{15}$

\section{Bulbar Urethra}

The surgical approach to primary urethral cancer of the bulbar urethra is determined by tumor stage. Transurethral resection can be appropriate for low stage lesions, however, repeat transurethral resection is required to ensure accurate staging. T2 tumors, if treated surgically, should be managed

Table 2 Management Options for Male Primary Urethral Cancer (PUC) by Anatomic Location

\begin{tabular}{|c|c|c|}
\hline Location & Extent of Disease & Management Options \\
\hline \multirow[t]{2}{*}{ Penile urethra } & Localized disease & $\begin{array}{l}\text { - Organ-sparing surgery if negative margin possible } \\
\text { - Radiation therapy if decline surgery }\end{array}$ \\
\hline & Advanced disease & $\begin{array}{l}\text { - Multimodal therapy Two cycles } 5 \text {-fluorouracil and mitomycin C, concurrent radia- } \\
\text { tion, consolidation surgery for nonresponders }\end{array}$ \\
\hline \multirow[t]{2}{*}{ Bulbar urethra } & $\leq \mathrm{TI}$ & - Consider transurethral resection \\
\hline & $\geq \mathrm{T} 2$ & $\begin{array}{l}\text { - Multimodal therapy Two cycles } 5 \text {-fluorouracil and mitomycin C, concurrent radia- } \\
\text { tion, consolidation surgery for nonresponders } \\
\text { - Neoadjuvant platinum-based chemotherapy and surgery }\end{array}$ \\
\hline \multirow[t]{2}{*}{$\begin{array}{l}\text { Prostatic urethra (primary } \\
\text { urothelial carcinoma) }\end{array}$} & No stromal invasion & $\begin{array}{l}\text { - TURP and BCG } \\
\text { - Cystoprostatectomy with lymphadenectomy for recurrence or progression }\end{array}$ \\
\hline & $\begin{array}{l}\text { Extensive ductal or } \\
\text { stromal invasion }\end{array}$ & - Cystoprostatectomy with lymphadenectomy \\
\hline
\end{tabular}

Note: a Surgery can include total penectomy, urethrectomy, possible cystoprostatectomy and pelvic lymphadenectomy.

Abbreviations: TURP, transurethral resection of the prostate; BCG, bacille Calmette-Guerin. 
with total penectomy and urethrectomy with possible cystoprostatectomy, and pelvic lymphadenectomy. ${ }^{29,35}$ In some cases, resection of the inferior pubic ramus is required to achieve negative margins. ${ }^{36}$ In select patients, organ preservation involving prostatourethrectomy with preservation of the glans and corpora cavernosa followed by chemoradiation has been described. ${ }^{37}$

Pathologic lymph node metastasis is a poor prognostic factor with a lower overall and cancer-specific survival. ${ }^{38}$ At the time of cystoprostatectomy, a template for pelvic lymphadenectomy similar to that of bladder urothelial cell carcinoma (UCC) can be utilized. However, tumors that extend from the bulbar urethra into the penile urethra may require both inguinal and pelvic lymphadenectomy. ${ }^{13,39}$

The low survival rates for surgical monotherapy (0-$40 \%$ ) and primary radiation monotherapy (five-year survival of $0-25 \%$ ) have prompted investigation of multimodal treatment approaches. ${ }^{15,17,36,40-42}$ Dalbagni et al described their single institution experience with PUC that included 40 patients managed with surgery and six managed with radiation and salvage surgery. Tumors located in the bulbar and penile urethra were included $(61 \%$ and $39 \%$ respectively). Five-year overall survival for the entire study cohort was $42 \%$ and was significantly lower for those with invasive vs superficial disease ( $36 \%$ vs $83 \%$ ) and bulbar vs distal tumors ( $26 \%$ vs $69 \%$ ). It was concluded that surgical monotherapy is inadequate, particularly for invasive disease. ${ }^{17}$ Therefore, multimodal therapy consisting of a combination of surgery, chemotherapy and radiation is often necessary.

The protocol of concurrent radiation, 5-fluorouracil, and mitomycin $\mathrm{C}$ that was developed by Cohen et al has been applied to bulbar urethral tumors as well. ${ }^{32}$ The previously discussed study by Kent et al also included 17 men (59\%) with bulbomembranous PUC. ${ }^{15}$ Survival outcomes were not stratified by tumor location. However, the findings remain applicable to men with advanced disease of the anterior urethra. All three patients who underwent salvage surgery for nonresponse to chemoradiation died of disease and two/six patients (33\%) that underwent salvage surgery for recurrence died of disease. Complications of salvage surgery occurred in $44 \%$ of patients, which highlights the challenges of salvage surgery in the postradiation setting.

Dayyani et al studied a cohort of 44 patients $(64 \%$ female) that underwent treatment with platinum based chemotherapy for advanced PUC. A notable proportion of patients in this study had positive lymph nodes (43\%) and $16 \%$ had distant metastatic disease. Surgery with adjuvant or neoadjuvant chemotherapy $(\mathrm{n}=28)$ resulted in an improved overall survival relative to chemotherapy alone (46.9 months vs 21.7 months, $p=0.02$ ). Specifically, neoadjuvant chemotherapy followed by surgery $(n=21)$ had a median overall survival of 25.6 months. The likely presence of selection bias makes comparison of overall survival rates between those receiving neoadjuvant and adjuvant chemotherapy difficult. However, the authors advocate for neoadjuvant chemotherapy to downstage the tumor prior to surgery, which may improve the success of surgery. Further, neoadjuvant chemotherapy avoids treatment delays due to postoperative complications that may exist in the setting of adjuvant chemotherapy. ${ }^{34}$

For men with $\mathrm{T} 2$ disease and clinically negative lymph nodes, the National Comprehensive Cancer Network (NCCN) guidelines recommend consideration of neoadjuvant chemotherapy or chemoradiation followed by urethrectomy with or without cystoprostatectomy and pelvic lymphadenectomy. Positive pathologic nodes or $\geq \mathrm{pT} 3$ disease can be managed with adjuvant chemotherapy or chemoradiation. Men with clinical T3 or T4 disease without clinically positive lymph nodes should preferably undergo chemoradiotherapy with or without consolidative surgery. Chemoradiation or chemotherapy with or without consolidative surgery are options for men with clinically node positive disease. ${ }^{29}$

In cases of recurrent PUC, there appears to be a benefit of salvage therapy. In a multi-institutional study by Gakis et al, the location of disease recurrence affected overall survival. The three-year overall survival was highest for no recurrence $(86.5 \%)$ followed by urethral recurrence $(74.5 \%)$ and nonurethral recurrence $(48.2 \%, p<0.05)$. Salvage therapy consisting of surgery or radiation with or without surgery resulted in a three-year overall survival ( $84.9 \%$ and $71.6 \%$ respectively) that was similar to patients without disease recurrence $(86.7 \%, p=0.65)$. In addition, salvage therapy had a significantly improved three-year overall survival compared to patients with recurrence and no salvage therapy $(38.0 \%, p<0.05)$ (Table 2). ${ }^{43}$

\section{Primary Urothelial Cancer of the Prostatic Urethra}

Prostatic urethral UCC is most commonly associated with synchronous involvement of the bladder. Cystoprostatectomy specimens of men with aggressive bladder cancer demonstrate synchronous prostatic UCC in $21-39 \%$ of cases. ${ }^{44,45}$ In addition, the prostate can be a site of UCC relapse after intravesical 
therapy for high risk, non-muscle invasive bladder tumors in $39 \%$ of patients. ${ }^{46}$ In contrast, primary prostatic UCC occurs in less than $4 \%$ of cases.

The management of urothelial carcinoma of the prostate is similar to that of urothelial carcinoma of the bladder. As such, the approach to treatment is determined by the invasiveness of the tumor and ranges from transurethral resection of the prostate (TURP) with bacille Calmette-Guerin (BCG) to radical cystoprostatectomy with extended lymphadenectomy. One of the challenges of the existing literature is that many studies include patients with concomitant bladder cancer, which makes it difficult to determine the isolated impact of UCC within the proximal urethra and prostate. It is important to note that UCC of the prostate is a distinct entity from the more aggressive proximal urethral squamous cell carcinoma or adenocarcinoma and requires a completely different treatment strategy as reviewed earlier.

\section{Organ Sparing Therapy}

Organ sparing therapy can be utilized for prostatic UCC without stromal invasion. This involves an aggressive TURP to remove all visible tumor followed by BCG delivered in once weekly instillations for six weeks. While data on the efficacy of TURP with BCG comes from several small, single institutional studies, a complete response has been demonstrated in 58-100\% of patients. ${ }^{47-51}$ The majority of these patients benefit from organ preservation as the minority (18-28\%) ultimately require cystoprostatectomy for disease recurrence or progression. ${ }^{48-50}$ Overall survival at a median follow-up of 27-90 months is $66-91 \%{ }^{48-50}$

The data on BCG without TURP for patients with carcinoma in situ of the prostatic urethra are limited. A small study $(\mathrm{n}=18)$ by Palou et al identified a complete response in $77 \%$ of cases. At a median followup of 31 months, cystectomy was required in $17 \%$ and overall survival was $89 \% .{ }^{52}$ Gofrit et al identified significant improvement in complete response among patients that had TURP with BCG compared with BCG alone (95\% vs 66\%). Given the sparse data for BCG monotherapy, TURP with BCG is recommended for patients with mucosal and limited ductal involvement (Table 2). ${ }^{50}$

\section{Cystoprostatectomy}

Initial cystoprostatectomy should be offered to patients with prostatic UCC that has extensive ductal involvement or stromal invasion. ${ }^{29}$ In addition, patients who fail TURP with BCG should undergo cystoprostatectomy. ${ }^{28}$ Stromal invasion is associated with a lower five-year overall survival relative to prostatic urethral and ductal involvement ( $25 \%$ vs $45 \%, p=0.024$ ), thus justifying more aggressive management with cystoprostatectomy. ${ }^{53}$ Among men with prostatic stromal invasion that underwent cystoprostatectomy, a lymph node mapping study found positive lymph nodes in $50 \%$ of patients with notable lymph node involvement above the bifurcation of the iliac vessels. ${ }^{54}$ Therefore, an extended lymph node dissection template has been recommended. ${ }^{28}$ Neoadjuvant chemotherapy consisting of methotrexate, vinblastine, doxorubicin, and cisplatin can provide downstaging and complete remission in $40 \%$ and $60 \%$ of patients with T2 to T4N0M0 UCC of the prostate respectively. ${ }^{55}$

\section{Female Primary Urethral Cancer \\ Anterior Urethra}

The management of anterior female PUC depends on the extent of tumor involvement. Endoscopic resection or laser therapy can be utilized for small, distal urethral tumors. In addition, partial urethrectomy is an alternative option for small, exophytic anterior urethral tumors. However, the data on local control with single modality urethral sparing approaches is underwhelming. A small observational study by DiMarco et al found a five-year disease-specific survival of $66 \%$ and five-year crude survival of $64 \%$. The most common complications were related to urinary continence with $42 \%$ developing new stress incontinence and $8 \%$ experiencing urinary retention. ${ }^{38}$

Bladder sparing surgical therapy has been described for carefully selected advanced anterior urethral tumors. This involves transvaginal radical urethrectomy with the limits of resection being the bulbocavernosus muscles bilaterally along with all adjacent periurethral soft tissue from the pubic symphysis to the bladder neck. The bladder neck is then closed and a catheterizable channel such as an appendicovesicostomy is created. ${ }^{13,38}$ Radical urethrectomy can offer the greatest opportunity for local cure in women with localized anterior PUC. ${ }^{28}$

Radiation therapy using brachytherapy, external beam radiation therapy, or both is an acceptable organ-sparing alternative to surgery in women with PUC. ${ }^{56}$ Five-year survival for anterior tumors is $71-74 \% .^{57,58}$ However, complications of radiotherapy can be notable and are observed in $16-49 \%$ of patients. Such complications include perineal desquamation, urethral stricture, radiation cystitis, and vesicovaginal fistula (Table 3). ${ }^{57,59}$ 
Table 3 Management Options for Female Primary Urethral Cancer (PUC) by Anatomic Location

\begin{tabular}{|c|c|}
\hline Location & Management Options \\
\hline $\begin{array}{l}\text { Anterior } \\
\text { urethra }\end{array}$ & $\begin{array}{l}\text { - Endoscopic resection } \\
\text { - Laser therapy } \\
\text { - Partial urethrectomy } \\
\text { - Radical urethrectomy } \\
\text { - Radiation therapy }\end{array}$ \\
\hline $\begin{array}{l}\text { Posterior } \\
\text { urethra }\end{array}$ & $\begin{array}{l}\text { - Multimodal therapy Chemotherapy, radiation, } \\
\text { anterior pelvic exenteration }{ }^{\mathrm{a}} \\
\text { - Neoadjuvant platinum-based chemotherapy and } \\
\text { anterior pelvic exenteration }{ }^{\mathrm{a}}\end{array}$ \\
\hline
\end{tabular}

Note: a Surgery can include cystectomy, urethrectomy, hysterectomy, oophorectomy, pelvic lymphadenectomy.

\section{Posterior Urethra}

In contrast to PUC of the anterior urethra, PUC involving the posterior female urethra has a lower five-year overall (54\% vs 25\%) and disease-specific survival (69\% vs $46 \%$ ) among patients undergoing treatment with surgery, radiotherapy, or combined modalities. ${ }^{22}$ Surgical management involves anterior pelvic exenteration and includes cystectomy, urethrectomy, hysterectomy, oophorectomy, and extended pelvic lymphadenectomy. ${ }^{35}$ The addition of vulvar or vaginal resections may also be necessary in order to achieve a negative margin. ${ }^{38}$ A single study by Dalbagni et al described a median survival after cystectomy of 36 months. $^{22}$ Another single institution series of 27 patients who underwent complete extirpative surgery noted a fiveyear crude and disease specific survival of $39 \%$ and $52 \%$ respectively. ${ }^{38}$ However, some of the patients had adjuvant radiation and/or chemotherapy, making it difficult to evaluate the outcomes of radical surgical therapy alone.

Radiation monotherapy has been described as an alternative to radical surgery. Milosevic et al described their experience with external radiation with and without brachytherapy for women with PUC. Among the 27 patients included in the study, $56 \%$ had proximal urethral involvement. Relapse-free rate was $37 \%$ and cause-specific survival was $20 \%$ over the median follow-up of 7.6 years. While the addition of brachytherapy to external radiation did improve local control, there was no improvement in cause-specific survival among women with proximal urethral involvement, advanced stage disease or tumors extending into adjacent organs. ${ }^{59}$ Retrospective data suggest that there is no difference in the rate of local recurrence following radiation vs surgery. ${ }^{22}$
As previously discussed, complications of radiotherapy are not uncommon. An MD Anderson series of 55 women with anterior or posterior PUC noted radiation-associated complications in 49\%. Overall, urethral stricture occurred in $20 \%$, fistula or necrosis in $18 \%$, and cystitis or hemorrhage in $11 \%{ }^{57}$

Multimodal therapy including a combination of chemotherapy, radiation, and surgery may provide the most benefit for women with advanced PUC, however, the specific combination or sequence of modalities remains to be elucidated. In the series by Dalbagni et al, neoadjuvant radiation followed by surgery was shown to significantly improve local recurrence-free survival. $^{22}$ As discussed earlier (male bulbar urethra section), a study by Dayyani et al that included a cohort both of men (36\%) and women (64\%) with advanced PUC found that neoadjuvant platinum-containing chemotherapy regimens followed by surgery provided an overall survival benefit relative to chemotherapy alone. Specifically, among the nine patients that had lymph node metastasis at the time of diagnosis, $44 \%$ were disease free at three-year followup (Table 3). ${ }^{34}$

\section{Management of Lymph Nodes in Female PUC}

Similar to male PUC, grossly positive lymph nodes are often indicative of metastatic disease and necessitate treatment. ${ }^{13}$ Management options recommended by the NCCN include chemoradiation alone vs chemoradiation or chemotherapy with or without consolidation lymphadenectomy. ${ }^{29}$

Nodal surveillance following management of the primary tumor is important. In a study from MD Anderson of 73 women with clinically negative lymph nodes who underwent radiation therapy to the primary tumor, nine developed nodal disease, of which only two patients survived. ${ }^{57}$ This has led some to call for further investigation of prophylactic management of clinically negative lymph nodes. ${ }^{13}$

\section{Conclusion}

PUC of the male and female urethra is exceedingly rare. As a result, the available data on the treatment of PUC is limited to studies with small sample sizes, retrospective design, and heterogenous cohorts. The current approach to treatment of PUC based on these data is largely determined by the location and extent of the tumor. Organ sparing approaches can be utilized for carefully selected patients with superficial and distal urethral lesions, 
whereas more advanced disease should be managed with multimodal therapy.

Ultimately, a significant knowledge gap remains in the treatment of PUC. The low incidence of disease should prompt future studies to focus on multi-institutional collaborations that are better powered to investigate specific treatment modalities and identify an optimal multimodal treatment strategy.

\section{Disclosure}

Alex J. Vanni is a consultant for Orchestra Biomed, Inc. The authors report no other conflicts of interest in this work.

\section{References}

1. Gatta G, Van Der Zwan JM, Casali PG, et al. Rare cancers are not so rare: the rare cancer burden in Europe. Eur $J$ Cancer. 2011;47 (17):2493-2511. doi:10.1016/j.ejca.2011.08.008

2. Visser O, Adolfsson J, Rossi S, et al. Incidence and survival of rare urogenital cancers in Europe. Eur J Cancer. 2012;48(4):456-464. doi:10.1016/j.ejca.2011.10.031

3. Swartz MA, Porter MP, Lin DW, Weiss NS. Incidence of primary urethral carcinoma in the United States. Urology. 2006;68 (6):1164-1168. doi:10.1016/j.urology.2006.08.1057

4. Narayan P, Konety B. Surgical treatment of female urethral carcinoma. Urol Clin North Am. 1992;19(2):373-382. doi:10.1016/ S0094-0143(21)00400-6

5. Wiener JS, Liu ET, Walther PJ. Oncogenic human papillomavirus type 16 is associated with squamous cell cancer of the male urethra. Cancer Res. 1992;52(18):5018-5023.

6. Cupp MR, Malek RS, Goellner JR, Espy MJ, Smith TF. Detection of human papillomavirus DNA in primary squamous cell carcinoma of the male urethra. Urology. 1996;48(4):551-555. doi:10.1016/S00904295(96)00246-4

7. Zinman LN, Vanni AJ. Management of proximal primary urethral cancer: should multidisciplinary therapy be the gold standard? Urol Clin North Am. 2016;43(4):505-513. doi:10.1016/j.ucl.2016.06.011

8. Thomas AA, Rackley RR, Lee U, Goldman HB, Vasavada SP, Hansel DE. Urethral diverticula in 90 female patients: a study with emphasis on neoplastic alterations. J Urol. 2008. doi:10.1016/j. juro.2008.08.040

9. Ahmed K, Dasgupta R, Vats A, et al. Urethral diverticular carcinoma: an overview of current trends in diagnosis and management. Int Urol Nephrol. 2010;42(2):331-341. doi:10.1007/s11255-009-9618-x

10. Greenwell TJ, Spilotros M. Urethral diverticula in women. Nat Rev Urol. 2015;12(12):671-680. doi:10.1038/nrurol.2015.230

11. Ray B, Canto AR, Whitmore WF. Experience with primary carcinoma of the male urethra. J Urol. 1977. doi:10.1016/S0022-5347(17) 58546-8

12. Rabbani F. Prognostic factors in male urethral cancer. Cancer. 2011;117(11):2426-2434. doi:10.1002/cncr.25787

13. Karnes RJ, Breau RH, Lightner DJ. Surgery for urethral cancer. Urol Clin North Am. 2010;37(3):445-457. doi:10.1016/j.ucl.2010.04.011

14. Zhang M, Adeniran AJ, Vikram R, et al. Carcinoma of the urethra. Hum Pathol. 2018. doi:10.1016/j.humpath.2017.08.006

15. Kent M, Zinman L, Girshovich L, Sands J, Vanni A. Combined chemoradiation as primary treatment for invasive male urethral cancer. J Urol. 2015;193(2):532-537. doi:10.1016/j.juro.2014.07.105
16. Gheiler EL, Tefilli MV, Tiguert R, De Oliveira JG, Pontes JE, Wood DP. Management of primary urethral cancer. Urology. 1998;52(3):487-493. doi:10.1016/S0090-4295(98)00199-X

17. Dalbagni G, Zhang ZF, Lacombe L, Herr HW. Male urethral carcinoma: analysis of treatment outcome. Urology. 1999;53 (6):1126-1132. doi:10.1016/S0090-4295(98)00659-1

18. Carroll PR, Dixon CM. Surgical anatomy of the male and female urethra. Urol Clin North Am. 1992;19(2):339-346. doi:10.1016/ S0094-0143(21)00397-9

19. Derksen JW, Visser O, de la Rivière GB, Meuleman EJ, Heldeweg EA, Lagerveld BW. Primary urethral carcinoma in females: an epidemiologic study on demographical factors, histological types, tumour stage and survival. World J Urol. 2013;31 (1): 147-153. doi:10.1007/s00345-012-0882-5

20. Dodson MK, Cliby WA, Keeney GL, Peterson MF, Podritz KC. Skene's gland adenocarcinoma with increased serum level of prostate-specific antigen. Gynecol Oncol. 1994;55(2):304-307. doi:10.1006/gyno.1994.1294

21. Dell'Atti L, Galosi AB. Female urethra adenocarcinoma. Clin Genitourin Cancer. 2018;16(2):e263-e267. doi:10.1016/j.clgc.2017.10.006

22. Dalbagni C, Zhang ZF, Lacombi- L, Hi-Rr HW. Female urethral carcinoma: an analysis of treatment outcome and a plea for a standardized management strategy. $\mathrm{Br} \quad J$ Urol. 1998;82 (6):835-841. doi:10.1046/j.1464-410X.1998.00878.x

23. Touijer AK, Dalbagni G. Role of voided urine cytology in diagnosing primary urethral carcinoma. Urology. 2004;63(1):33-35. doi:10.1016/ j.urology.2003.08.007

24. Donat SM, Wei DC, McGuire MS, Herr HW. The efficacy of transurethral biopsy for predicting the long-term clinical impact of prostatic invasive bladder cancer. $J$ Urol. 2001;165(5):1580-1584. doi:10.1016/s0022-5347(05)66352-5

25. Stewart SB, Leder RA, Inman BA. Imaging tumors of the penis and urethra. Urol Clin North Am. 2010;37(3):353-367. doi:10.1016/j. ucl.2010.04.014

26. Gourtsoyianni S, Hudolin T, Sala E, Goldman D, Bochner BH, Hricak H. MRI at the completion of chemoradiotherapy can accurately evaluate the extent of disease in women with advanced urethral carcinoma undergoing anterior pelvic exenteration. Clin Radiol. 2011;66(11):1072-1078. doi:10.1016/j.crad.2011.07.039

27. American Joint Committee on Cancer. The AJCC cancer staging manual, 8th edition. Am Coll Surg. 2018.

28. Gakis G, Witjes JA, Compérat E, et al. EAU guidelines on primary urethral carcinoma. Eur Urol. 2013;64(5):823-830. doi:10.1016/j. eururo.2013.03.044

29. Flaig TW, Spiess PE, Agarwal N, et al. Bladder cancer, version 3.2020, NCCN clinical practice guidelines in oncology. J Natl Compr Cancer Netw. 2020;18(3):329-354. doi:10.6004/jnccn.2020.0011

30. Smith Y, Hadway P, Ahmed S, Perry MJ, Corbishley CM, Watkin NA. Penile-preserving surgery for male distal urethral carcinoma. BJU Int. 2007;100(1):82-87. doi:10.1111/j.1464410X.2007.06901.x

31. Heysek RV, Parsons JT, Drylie DM, Million RR. Carcinoma of the male urethra. J Urol. 1985;134(4):753-755. doi:10.1016/S00225347(17)47424-6

32. Cohen MS, Triaca V, Billmeyer B, et al. Coordinated chemoradiation therapy with genital preservation for the treatment of primary invasive carcinoma of the male urethra. J Urol. 2008;179(2):536-541. doi:10.1016/j.juro.2007.09.068

33. Nigro ND, Vaitkevicius VK, Considine B. Combined therapy for cancer of the anal canal: a preliminary report. Dis Colon Rectum. 1993;36(7):709-711. doi:10.1007/BF02238600

34. Dayyani F, Pettaway CA, Kamat AM, Munsell MF, Sircar K, Pagliaro LC. Retrospective analysis of survival outcomes and the role of cisplatin-based chemotherapy in patients with urethral carcinomas referred to medical oncologists. Urol Oncol Semin Orig Investig. 2013. doi:10.1016/j.urolonc.2012.01.011 
35. Anderson CB, McKiernan JM. Tumors of the urethra. In: Partin A, Peters C, Kavoussi L, editors. Campbell-Walsh Urology. 12th ed. Philadelphia: Elsevier; 2020:1776-1789e3.

36. Dinney CPN, Johnson DE, Swanson DA, Babaian RJ, Von Eschenbach AC. Therapy and prognosis for male anterior urethral carcinoma: an update. Urology. 1994;43(4):506-514. doi:10.1016/ 0090-4295(94)90242-9

37. Christopher N, Arya M, Brown RSD, Payne HA, Woodhouse CRJ, Ralph DJ. Penile preservation in squamous cell carcinoma of the bulbomembranous urethra. BJU Int. 2002;89(4):464-465. doi:10.1046/j.1464-4096.2001.00135.x

38. DiMarco DS, DiMarco CS, Zincke H, et al. Surgical treatment for local control of female urethral carcinoma. Urol Oncol Semin Orig Investig. 2004. doi:10.1016/S1078-1439(03)00174-1

39. Janisch F, Abufaraj M, Fajkovic H, et al. Current disease management of primary urethral carcinoma. Eur Urol Focus. 2019;5 (5):722-734. doi:10.1016/j.euf.2019.07.001

40. Farrer JH, Lupu AN. Carcinoma of deep male urethra. Urology. 1984;24(6):527-531. doi:10.1016/0090-4295(84)90095-5

41. Mandler JI, Pool TL. Primary carcinoma of the male urethra. J Urol. 1966;96(1):67-72. doi:10.1016/S0022-5347(17)63207-5

42. Kaplan GW, Bulkey GJ, Grayhack JT. Carcinoma of the male urethra. J Urol. 1967;98(3):365-371. doi:10.1016/S0022-5347(17)62892-1

43. Gakis G, Schubert T, Morgan TM, et al. The prognostic effect of salvage surgery and radiotherapy in patients with recurrent primary urethral carcinoma. Urol Oncol Semin Orig Investig. 2018. doi:10.1016/j.urolonc.2017.09.012

44. Bruins HM, Djaladat $\mathrm{H}$, Ahmadi $\mathrm{H}$, et al. Incidental prostate cancer in patients with bladder urothelial carcinoma: comprehensive analysis of 1476 radical cystoprostatectomy specimens. J Urol. 2013;190 (5):1704-1709. doi:10.1016/j.juro.2013.05.034

45. Patel SG, Cookson MS, Barocas DA, Clark PE, Smith JA, Chang SS. Risk factors for urothelial carcinoma of the prostate in patients undergoing radical cystoprostatectomy for bladder cancer. BJU Int. 2009;104(7):934-937. doi:10.1111/j.1464-410X.2009.08525.x

46. Herr HW, Machele donat S. Prostatic tumor relapse in patients with superficial bladder tumors: 15- year outcome. J Urol. 1999. doi:10.1016/S0022-5347(05)68826-X

47. Canda AE, Tuzel E, Mungan MU, Yorukoglu K, Kirkali Z. Conservative management of mucosal prostatic urethral involvement in patients with superficial transitional cell carcinoma of the bladder. Eur Urol. 2004;45(4):465-470. doi:10.1016/j.eururo.2003.12.014

48. Palou Redorta J, Schatteman P, Huguet Pérez J, et al. Intravesical instillations with bacillus calmette-guérin for the treatment of carcinoma in situ involving prostatic ducts. Eur Urol. 2006;49 (5):834-838. doi:10.1016/j.eururo.2005.12.019
49. Taylor JH, Davis J, Schellhammer P. Long-term follow-up of intravesical bacillus Calmette-Guérin treatment for superficial transitional-cell carcinoma of the bladder involving the prostatic urethra. Clin Genitourin Cancer. 2007;5(6):386-389. doi:10.3816/CGC.2007. n. 021

50. Gofrit ON, Pode D, Pizov G, Zorn KC, Katz R, Shapiro A. Prostatic urothelial carcinoma: is transurethral prostatectomy necessary before bacillus Calmette-Guérin immunotherapy? BJU Int. 2009;103 (7):905-908. doi:10.1111/j.1464-410X.2008.08210.x

51. Hillyard RW, Ladaga L, Schellhammer PF. Superficial transitional cell carcinoma of the bladder associated with mucosal involvement of the prostatic urethra: results of treatment with intravesical bacillus Calmette-Guerin. J Urol. 1988;139(2):290-293. doi:10.1016/S00225347(17)42389-5

52. Palou J, Xavier B, Laguna P, Montlleó M, Vicente J. In situ transitional cell carcinoma involvement of prostatic urethra: bacillus calmette-guérin therapy without previous transurethral resection of the prostate. Urology. 1996;47(4):482-484. doi:10.1016/S00904295(99)80481-6

53. Ngninkeu BN, Lorge F, Moulin P, Jamart J, Van Cangh PJ. Transitional cell carcinoma involving the prostate: a clinicopathological retrospective study of 76 cases. $J$ Urol. 2003;169(1):149-152. doi:10.1016/s0022-5347(05)64056-6

54. Vazina A, Dugi D, Shariat SF, Evans J, Link R, Lerner SP. Stage specific lymph node metastasis mapping in radical cystectomy specimens. $J$ Urol. 2004;171(5):1830-1834. doi:10.1097/01. ju.0000121604.58067.95

55. Scher HI, Yagoda A, Herr HW, et al. Neoadjuvant M-VAC (methotrexate, vinblastine, doxorubicin and cisplatin) for extravesical urinary tract tumors. J Urol. 1988. doi:10.1016/S0022-5347(17)42496-7

56. Koontz BF, Lee WR. Carcinoma of the urethra: radiation oncology. Urol Clin North Am. 2010;37(3):459-466. doi:10.1016/j. ucl.2010.04.007

57. Garden AS, Zagars GK, Delclos L. Primary carcinoma of the female urethra results of radiation therapy. Cancer. 1993;71(10):3102-3108. doi:10.1002/1097-0142(19930515)71:10<3102::aidcncr2820711034>3.0.CO;2-2

58. Weghaupt K, Gerstner GJ, Kucera H. Radiation therapy for primary carcinoma of the female urethra: a survey over 25 years. Gynecol Oncol. 1984. doi:10.1016/0090-8258(84)90060-X

59. Milosevic MF, Warde PR, Banerjee D, et al. Urethral carcinoma in women: results of treatment with primary radiotherapy. Radiother Oncol. 2000;56(1):29-35. doi:10.1016/S0167-8140(00)00208-5
Research and Reports in Urology

\section{Publish your work in this journal}

Research and Reports in Urology is an international, peer-reviewed, open access journal publishing original research, reports, editorials, reviews and commentaries on all aspects of adult and pediatric urology in the clinic and laboratory including the following topics: Pathology, pathophysiology of urological disease; Investigation and treatment of urological disease; Pharmacology of drugs used for the treatment of urological disease. The manuscript management system is completely online and includes a very quick and fair peer-review system, which is all easy to use. Visit http://www.dovepress.com/ testimonials.php to read real quotes from published authors. 